\title{
Sobre o feminicídio, o direito da mulher de nomear suas experiências
}

\author{
About feminicide, the woman's right to name her experiences
}

\author{
Jackeline Aparecida Ferreira Romio ${ }^{a}$
}

\begin{abstract}
Resumo No artigo argumenta-se a necessidade de analisar a violência e a morte de mulheres de maneira a entendê-la dentro do quadro complexo das políticas de controle do corpo e sexualidade. Este tipo de abordagem tem sido especialmente produzido por feministas através da caracterização do fenômeno denominado feminicídio. $\mathrm{O}$ texto analisa e explica como o conceito de feminicídios foi se modernizando e se amplificando e se adequando às realidades nacionais latino-americanas ao se propagarem enquanto lei.
\end{abstract} Palavras-chave Feminicídio; Feminicídio na América Latina; Feminicídio no Brasil; Violência doméstica; Violência sexual; Violência reprodutiva; Desigualdades.

Abstract The article argues the need to analyze the violence and death of women looking for understand it within the complex framework of the policies of control the body and sexuality of woman. This approach has been especially produced by feminists through the characterization of the phenomenon called feminicide. The article analyzes and explains how the concept of feminicide has been modernized and amplified in the conceptual field and adjusted to Latin American national realities and law.

Keywords Feminicide; Feminicide in Latin America; Feminicide in Brazil; Domestic violence; Sexual violence; Reproductive violence; Inequalities.

\section{INTRODUÇÃO}

Este artigo é derivado do trabalho desenvolvido anteriormente em tese de doutorado sobre o tema dos feminicídios no Brasil. Parte-se da tentativa de tipificar e mensurar suas ocorrências por meio de fontes secundárias de informação produzidas pelo setor da saúde, com o objetivo de auxiliar na monitoração e diagnóstico da crescente violência de gênero contra mulheres. $\mathrm{O}$ texto analisa e explica como o conceito de feminicídios foi se modernizando e se amplificando no campo conceitual e se adequando às realidades nacionais latino-americanas ao se

a Doutora em Demografia pela UNICAMP, em Tese de doutorado defendida em 2017, intitulada "Feminicídios no Brasil, uma proposta de análise com dados da saúde". O artigo aqui apresentado toma como base o tópico "feminicídio sexual" da tese. 
propagarem enquanto lei. Ao final apresenta entendimento da autora e proposta de nova tipologia sintética dos vários caminhos que levaram a definição atual do feminicídios.

\section{ORIGENS DO CONCEITO DE FEMINICÍDIO}

O conceito de feminicídio surge em meados dos anos 1970 no movimento feminista, como uma nova forma de nomear as mortes de mulheres por homicídio devido a sua condição social de mulher, e de se opor a aparente neutralidade do termo homicídio, que designava as mortes por assassinato sem a observação sobre as diferenças de sexo e gênero nestas mortes. O conceito de feminicídio (femicide em inglês), um neologismo, começa a disputar o campo da epistemologia dos direitos humanos.

A primeira vez que o termo feminicídio foi utilizado ocorreu durante as sessões do Primeiro Tribunal Internacional de Crimes contra as Mulheres, em Bruxelas, Bélgica, em 1976. Neste tribunal sobre mortes de mulheres nos Estados Unidos e no Líbano, a ativista feminista Diana Russell testemunhou e defendeu que tais ocorrências seriam consequência de ações misóginas e, como tal, deveriam ser apresentadas e julgadas como feminicídios (femicide). O conceito exposto naquele tribunal englobaria uma variedade de violências contra as mulheres que resultam em morte, desde a prática de queimar mulheres consideradas bruxas no passado aos infanticídios de meninas, ou os casos de assassinatos justificados por motivos de honra. A ativista tinha como objetivo demonstrar que este tipo de crime tem sido praticado ao largo do tempo, e por diferentes justificativas (Russell, 2011).

Posteriormente, em 1992, Diana Russell e Jill Radford lançam o livro Femicide: the politics of woman killing, composto por diversos artigos escritos por pesquisadoras e ativistas dos direitos humanos das mulheres sobre o tema dos feminicídios, entre os anos 1980 e 1990. As autoras analisaram a ocorrência do fenômeno nos Estados Unidos, Reino Unido e Índia, acrescentando discussões como o racismo, a violência sexual sistemática e a lesbofobia como dimensões importantes a serem consideradas. (RUSSELL; RADFORD, 1992).

Na introdução ao livro, Jill Radford, coeditora da obra, define os feminicídios da seguinte maneira:

Feminicídio (femicide) é o assassinato misógino de mulheres por homens, ele é uma forma de violência sexual. Como definido por Liz Kelly, a violência sexual pode ser considerada como "qualquer tipo de ato físico, visual, verbal ou sexual experimentado por mulheres ou meninas que tenha gerado qualquer efeito que 
fira, degrade ou tire as habilidades de controlar contatos íntimos” (KelLy, 1988, p. 41).

Esta definição está no livro Surviving Sexual Violence (1988) em que ela estabeleceu o conceito do "continuum de violência", marco para o desenvolvimento do conceito de feminicídio que evidencia um desencadeamento de violências que pode resultar na morte da mulher. Interno a esta definição está o reconhecimento da dissonância entre as percepções e experiências de mundo social e da violência sexual entre mulheres e homens, a visão dá prioridade às experiências e entendimentos das mulheres sobre as intenções dos homens, assim como é consistente com uma das bases do feminismo: o direito da mulher em nomear suas experiências (RADFORD, 1992, p. 3).

Para Radford (1992), esta forma de tratar a violência sexual desenvolvida pela socióloga Liz Kelly amplia a possibilidade de entendimento, pois focaliza o olhar para o desejo de poder, dominação e controle, esta conceituação enxerga a agressão sexual praticada por homens em relação a todas as opressões da mulher na sociedade patriarcal. ${ }^{1} \mathrm{O}$ que também permite fazer conexões entre as várias formas de violência sexual, ou seja, um "continuum da violência sexual", onde o estupro, assédio sexual, pornografia, e abuso físico de mulheres e crianças são todas diferentes expressões da violência sexual praticada por homens e não formas discretas ou desconectadas entre si (RADFORD, 1992, p. 3).

A autora acredita que esta resignificação pode ser mais sensível às percepções da violência a partir do ponto de vistas das mulheres em comparação a uma visão legal sobre ela, que tende a ser enviesada pelas considerações racistas, heterossexistas e moralistas imbricadas nos aparelhos da justiça e segurança pública, ou seja, a observação do continuum da violência sexual contra as mulheres permite identificar e endereçar o leque de experiências heterossexuais forçadas e coercivas, que mulheres são submetidas, facilitando a análise da violência sexual masculina como forma central da manutenção do patriarcado. A autora localiza o feminicídio dentro deste continuum, desmascarando a tendência de retratar e interpretar os agressores como bestas ou animais (tipo de homem que foge dos padrões de "normalidade"), o colocando nos termos das políticas sexuais de apropriação das mulheres (RADFORD, 1992, p. 4).

Outros fatores evidenciados por Radford dizem respeito ao silêncio e a banalização envolvida no tratamento geral destas mortes pelo sistema de justiça e pela

1 Dominação masculina + subordinação feminina = sociedade patriarcal. 
mídia sensacionalista. Quando uma mulher é assassinada não há sobreviventes para contar sua história, não há depoimentos, nos restam os documentos oficiais de notificação das mortes por parte das autoridades e os relatos de parentes da vítima, do agressor e das testemunhas. Nos casos de agressão contra a mulher há uma tendência em transformá-la na própria responsável pela agressão que sofreu (RADFORD, 1992, p. 6).

Abordando as questões estruturais da violência sexual perpetrada por homens, a pesquisadora elucida que este tipo de violência tem sido definida como característica da sociedade patriarcal, modo central pelo qual homens detêm poder sobre mulheres e criança, manifestando-se como outras formas de opressão, como o racismo, na discriminação econômica e legal, como toda forma de opressão estrutural está enraizada na violência. O feminicídio serve para controlar as mulheres enquanto classe de sexo e é fundamental para a manutenção do status quo do patriarcado. A definição de Radford está bastante ligada às concepções de violência da teoria feminista radical, que busca especialmente evidenciar as estruturas patriarcais da opressão das mulheres (RADFORD, 1992, p. 6).

Em outro texto da coletânea Femicide (1992), Jane Caputi e Diana Russel definem o feminicídio da seguinte forma:

Assim como o estupro, muitos assassinatos de mulheres por maridos, amantes, pais, conhecidos e estranhos, não são produtos de algum desvio inexplicável, eles são feminicídios (femicides), a forma mais extrema do terrorismo sexista, motivado pelo ódio, desprezo, prazer, ou um senso de propriedade sobre a mulher. Feminicídio inclui mortes por mutilação, estupro, espancamentos que terminam em morte, imolação como no caso das mulheres consideradas bruxas na Europa ou de viúvas na Ásia, crimes de honra [...] nomeando-os como feminicídio remove-se o véu não engendrado de termos como homicídio e assassinato (CAPUTI; RuSSELL, 1992, p. 15; em livre tradução).

Para as autoras,

...o feminicídio fala sobre o extremo fim do continuum de terror anti-mulher que inclui uma variedade de formas de violências e abusos físicos e verbais, como o estupro, a tortura, escravidão sexual (particularmente na prostituição), incestos e extrafamiliar abuso sexual de crianças, violência física e emocional, assédio sexual (por telefone, nas ruas, no trabalho, e na escola), mutilação genital (clitoridetomia, excisão, infibulação), operações ginecológicas desnecessárias 
(histerectomias gratuitas), heterossexualidade forçada, esterilização forçada, maternidade forçada (pela criminalização da contracepção e do aborto), psicocirurgia, negação de alimentos para mulheres em algumas culturas, cirurgias estéticas e outras mutilações em nome da beleza. Sempre que estas formas de terrorismo resultam em morte, eles se tornam feminicídios (CAPUTI; RusselL, 1992, p. 15; em livre tradução).

Em outro texto da coletânea, sobre as releituras dos assassinatos de mulheres na história da Europa, Marriane Hester trata da perseguição às bruxas na Europa continental, na Escócia e na Inglaterra, séculos XVI e XVII, período no qual milhares de mulheres foram condenadas ao aprisionamento e morte por acusação de bruxaria, o que ela nomeou como "feminicídio encoberto historicamente" (HESTER, 1992, p. 30).

A autora atenta para o contexto demográfico dos séculos XVI e XVII, quando a população estava em mudança e as mulheres eram mais numerosas que os homens, para as classes baixas os casamentos ocorriam cada vez mais tarde. Entre pequenos proprietários de terra e trabalhadores a idade média ao primeiro casamento era bem alta no século XVII, crescendo de 27 anos para 28 anos para os homens e de 25 para 27 anos para as mulheres. As circunstâncias de dificuldades econômicas fizeram com que não se pudesse manter economicamente um casamento antes disso. O efeito desse adiamento no matrimônio foi o crescimento do número de pessoas não casadas, especialmente de mulheres, e de mulheres vivendo fora do controle masculino. Dentro deste contexto as mulheres sozinhas eram ativamente competitivas com os homens para sobreviver em uma situação de escassez de recursos, o caso particular da mulher camponesa, que foi a mais afetada pela perseguição às bruxas, em especial as idosas (HESTER, 1992, p. 30).

As proposições dos artigos compilados no livro Femicide: the politics of killing women tornaram-se marcos conceituais para qualquer pesquisa que procure entender o assassinato de mulheres partindo do ponto de vista feminista e que considere a interação das opressões, especialmente as de gênero, raça, classe e sexualidade. O objetivo da compilação foi nomear o feminicídio e o identificar como um tema urgente tanto para feministas como para pessoas que lutam pelo fim da violência contra as mulheres. Para elas, feminicídio localiza-se no contexto das políticas sexuais balizadoras da opressão patriarcal.

Em discurso mais atual, Russell rediscute suas contribuições iniciais sobre o conceito feminicídio e ressalta a importância das escolhas referentes à grafia do termo. Para ela, a utilização do prefixo 'Fem' faz referência ao termo em inglês 
'Female' e não ‘women', pois em inglês o termo 'women' restringe a idade da mulher ao período adulto/reprodutivo do ciclo de vida, o que não era a intenção da autora que desejava englobar no conceito de feminicídio mulheres de várias faixas etárias, sejam elas meninas, adolescentes, adultas ou idosas. Essa pontuação poderia ser feita também com base no português brasileiro onde a palavra 'mulher' restringe a idade da mulher a fase adulta do ciclo de vida. Ao longo dos anos o termo femicide passou a ser grafado de duas formas em países de língua castelhana e portuguesa, ora como femicídio, ora como feminicídio. Para algumas autoras, que desenvolveram posteriormente trabalhos sobre tema, as diferenças não recaem apenas na forma gráfica da palavra, mas também nos conceitos inerentes a cada grafia escolhida. Como exemplo, para algumas autoras a opção pela grafia feminicídio faz sentido por eliminar possíveis interpretações que equivalem o femicídio ao homicídio, o que resultaria em reducionismo do potencial do conceito (RusselL, 2011). Esta última interpretação é também a opção para esta tese, em que se grafa o conceito como feminicídios, reduzindo ao máximo os ruídos que esta nova perspectiva possa sofrer.

Russell (2011) acrescenta que também são feminicídios as mortes de mulheres por abortos malsucedidos nos países com governos regidos por premissas patriarcais e religiosas que os proíbem em suas legislações, assim como as mortes decorrentes das epidemias de AIDS e da infecção decorrente de estupros, e comportamentos sexistas, como chacinas com maioria de vítimas mulheres.

Nestes textos ficam evidentes duas formas de feminicídio, uma direta, especificamente os assassinatos de mulheres por homens, e outra indireta, que seriam as outras formas de violência patriarcal que termina em morte, sobretudo as formas institucionais, como a proibição do aborto e outras políticas de controle de sexualidade e do corpo feminino que termine em morte, assim como a negligência dos Estados em coibir, punir e erradicar as formas diretas, pois a negligência do Estado promove violência e o senso de segurança e justiça se desloca da esfera pública dos direitos para se tornar uma responsabilidade individual.

\section{A DISSEMINAÇÃO E TRADUÇÃO DO CONCEITO FEMINICÍDIO NA AMÉRICA LATINA}

No início da década de 1990, começa a crescer o número de denúncias de assassinato de mulheres jovens trabalhadoras das maquiladoras ${ }^{2}$ na região de

2 Empresas de montagem e acabamento de produtos para exportação, em sua grande maioria dos EUA e Japão, produzem especialmente eletroeletrônicos, peças de automóveis e têxteis. Este tipo de empresas são características da região fronteiriça do México e contam com expansão e incentivos fiscais para seu desenvolvimento desde a década de 1960. Elas são também a forma 
fronteira entre o México e os EUA, Ciudad Juárez, Chihuahua. A violência sexual, mutilação, desfiguração e abandono dos corpos em vias e locais públicos, no contexto das mortes, chamavam a atenção da mídia e opinião pública, causando revolta na população. Nesse momento se iniciam uma série de mobilizações pela defesa dos direitos humanos das mulheres e por justiça para as vítimas e seus familiares. A partir deste contexto, tem entrada na América Latina o conceito de feminicídios como conceito que define esta morte específica de mulheres.

$\mathrm{O}$ entendimento dado aos assassinatos de mulheres mexicanas dentro da concepção do feminicídio tem como foco as questões de classe social e raça/etnia e desloca o olhar mais voltado ao agressor íntimo para a negligência por parte do Estado mexicano na ação frente aos assassinatos, inclusive pela ausência de investigação ou montagem de respostas institucionais rápidas centradas em apresentar culpados. Outro debate que o caso mexicano promoveu foi refletir sobre as questões estruturais relacionadas ao avanço do modo de produção neoliberal e sua relação com as mortes, como a instalação das multinacionais na região fronteiriça do México e consequente migração interna feminina em busca de trabalho na região (Lagarde, 2006; FAlquet, 2014).

As condições de trabalho das mulheres nas fábricas maquiladoras e a ausência de políticas nacionais destinadas ao desenvolvimento social desta região compõem o contexto socioeconômico e político destas mortes, além dos aspectos políticos e de controle militar ao longo da história do país. Falquet (2014) ressalta que tais contextos são comparáveis a histórias semelhantes de ditadura e pós-guerra no continente americano (FALQUET, 2014).

Dan La Botz (1999) remonta a morte da adolescente Irma Angelica Rosales, 13 anos, estuprada e assassinada no caminho entre seu trabalho e sua casa na Ciudad Juárez, fronteira com a cidade de El Paso, Texas. Para ele, mortes como a dela são símbolos do poder corporativo, do trabalho infantil e da exploração das mulheres na fronteira, pois as corporações multinacionais maquiladoras (EUA) teriam sido implantadas na fronteira dos EUA-México justamente em função da exploração do trabalho de jovens mulheres como Irma. As jovens eram maioria das trabalhadoras nessas indústrias ${ }^{3}$ e coexistiu a dicotômica situação entre a

de industrialização desta região do México, uma marca são os baixos salários e a alta exploração trabalhista.

3 Embora as jovens só possam ser empregadas com a idade de 16 anos, era comum naquela época o emprego de menores de idade de 12, 13 e 14 anos, através de documentação falsa. 
infraestrutura que o governo ofereceu às empresas maquiladoras e a contrapartida social oferecida para as comunidades do entorno (LA BотZ, 1999) ${ }^{4}$.

Enquanto as corporativas multinacionais como General Motors, Ford, General Electric, Johnson \& Johnson obtinham de suas parcerias com o governo mexicano e estadunidense apoio para construção de parques industriais modernos com enormes possibilidades de estacionamento para caminhões, redes de eletricidade de alta tensão e, em alguns casos, exteriores paisagísticos, os trabalhadores viviam em condições sub-humanas.

Os governos dos EUA e do México em parceria com as empresas privadas construíram superautoestradas, estradas de ferro e aeroportos para servir a zona maquiladora. Em contrapartida, os trabalhadores vivem em barracos e nos destroços da produção industrial, em ruas sem asfalto, em locais sem água corrente, esgotos ou eletricidades, com escolas superlotadas, muitas jovens trabalhando sem frequentar escola, além da novidade do crack. Os traficantes de drogas, policiais e até mesmo o Exército mexicano cooperavam no movimento de drogas através da fronteira. Violência policial, tiroteios de facções rivais, disseminada presença de seguranças particulares para os ricos e fábricas ameaçavam a segurança dos cidadãos comuns. (LA BотZ, 1999; em livre tradução)

A partir da década de 90 começa a ser aplicado o conceito de feminicídios no México e então a ser disseminado para outros países da América Latina. Dentre as vozes surge a da antropóloga e congressista mexicana Marcela Lagarde, que influenciada pelos estudos de Russell e Radford (1992), traduziu o termo do inglês femicide para a forma castelhana feminicídio para compreender e intervir politicamente nas mortes daquelas jovens.

Marcela Lagarde foi a principal estudiosa feminista mexicana a se pronunciar sobre feminicídios, ela atualizou o conceito feminicídio para denominar o conjunto de violações aos direitos humanos das mulheres que existem nas mortes e desaparecimentos de mulheres no México, além de entendê-los como crimes de lesa a humanidade (LAGARDE, 2008, p. 216).

O feminicídio é o genocídio contra as mulheres e acontece quando as condições históricas geram práticas sociais que permitem atentados violentos contra a integridade, a saúde, a liberdade e a vida de meninas e mulheres (LAGARDE, 2008, p. 216).

4 http://corpwatch.org/article.php?id=798 
Segundo Lagarde, o conceito de feminicídios endereça os crimes contra crianças e mulheres ao patriarcado, considerando que eles expressam o fim extremo da dominação de gênero contra as mulheres. Ela identifica vários tipos de agentes desta violência, que podem ser pessoas de vários tipos de relação com as vítimas e ressalta aspectos da motivação ligada ao ódio, tais como:

parceiros, ex-parceiros, namorados, esposos, acompanhantes, familiares, visitas, colegas e companheiros de trabalho, ou por militares, desconhecidos e anônimos. Também é relatada a existência de grupos mafiosos de delinquentes ligados ao crime e suas linguagens. Uma marca destes crimes é o alto teor de crueldade e de fato serem crimes de ódio contra mulheres (LAGARDE, 2008, p. 216).

Para a autora, o "feminicídio demonstra a desigualdade estrutural entre mulheres e homens e como a dominação dos homens sobre as mulheres encontra na violência de gênero um mecanismo de reprodução da opressão de mulheres". Quando o Estado e suas autoridades designadas para prevenir e erradicar estes crimes agem de maneira negligente, ineficiente e preconceituosa, e coexiste na sociedade uma cegueira de gênero ou preconceitos sexistas e misóginos sobre as mulheres, a pesquisadora considera que se cria a condição para a existência de feminicídios e que este passa a ser um crime de Estado (LAGARDE, 2008, p. 217).

Marcela Lagarde foi deputada de 2003 a 2007, no México, pelo Partido de La Revolucion Democrática (PRD), período em que atuou para a tipificação do crime de feminicídio. No período anterior ao seu mandato, existiu uma comissão especial de investigação dos homicídios de meninas e mulheres na Ciudad Juárez. A comissão utilizava algumas informações sobre os homicídios existentes, mesmo que em forma incipiente. Nesse período foram apresentadas diversas denúncias sobre crimes contra as mulheres de outras partes do país (LAGARDE, 2008, p. 218).

Para dar conta da complexidade dos casos no território mexicano, sob a liderança de Lagarde, foi criada a comissão especial de acompanhamento aos feminicídios em toda a República Mexicana. Houve muitos avanços conceituais e políticos durante este processo, primeiro por tratar dos casos em todo o país e não somente na Ciudad Juárez e por nomear os crimes com a terminologia dos feminicídios e não mais como homicídios, optando pelo tratamento dos casos desde uma perspectiva de gênero. Aos poucos a 
comissão parlamentar começou a trabalhar com a questão de acolhimento das denúncias e de exigência de justiça (LAGARDE, 2008, p. 218-219).

\begin{abstract}
A Investigación Diagnóstica sobre a Violencia Feminicida en la República Mexicana foi a primeira pesquisa científica qualitativa e quantitativa sobre a violência de gênero contra as mulheres realizada no México a partir de uma perspectiva feminista sobre gênero e direitos humanos das mulheres. O principal objetivo era documentar especificamente a situação do feminicídio no país, ao localizar o feminicídio como parte da violência doméstica e outras formas de violências investigadas (LAGARDE, 2008, p. 10; em livre tradução).
\end{abstract}

A comissão utilizou informação oficial dos ocorridos de 1999 a 2006, com dados sobre os homicídios dolosos e culposos. Os crimes de feminicídios foram entendidos dentro do marco da violência de gênero e das relações com todas as formas de violência contra meninas e mulheres. Segundo os achados da investigação, o perfil destas mulheres é variado em suas idades e classe social, mas se concentra em mulheres jovens, pobres e marginalizadas. As vítimas sofreram variadas formas de tortura e violência (LAGARDE, 2008, p. 222).

A perspectiva teórica que o grupo adotou acabou por demonstrar várias outras mortes violentas de meninas e mulheres. A investigação descobriu números alarmantes sobre acidentes domésticos, de trânsito e de suicídios. Foi revelado um elevado número de mulheres mortas por questões ligadas à saúde reprodutiva - como por câncer no colo de útero e ovários - e confirmado que as mortes maternas ocupavam o primeiro lugar nas taxas de mortalidade de mulheres em idade reprodutiva. Estudos regionais evidenciaram diferenças marcantes entre as várias regiões e cidades do México, revelando realidades complexas e diferenciadas por região (LAGARDE, 2008, p. 224- 225).

Para Lagarde, os resultados da Investigação Diagnóstica dos feminicídios permitiram comprovar as variadas teses teóricas sobre eles, entre elas, o fato da violência contra as mulheres ser "grave, complexa e multifatorial, fruto da articulação sinergética de um conjunto de determinações baseadas na dominação e no sexo". Alerta para a questão do racismo, classismo, lesbofobia e outras formas de opressão correlacionadas (LAGARDE, 2008, p. 232).

O feminicídio é uma das formas extremas de violência de gênero e está conformado pelo conjunto de feitos violentos misóginos contra as mulheres que implica na violação de seus direitos humanos, atentam contra sua segurança e põe risco 
a sua vida. Culmina no assassinato de algumas meninas e mulheres. Há infinidades de sobreviventes. O feminicídio se consuma porque as autoridades omissas, negligentes ou em conluio com agressores, exercem sobre as mulheres violência institucional ao obstaculizar seu acesso à justiça e com ele contribuem para a impunidade. O feminicídio acarreta a ruptura parcial do estado de direito, já que o Estado é incapaz de garantir a vida das mulheres, de respeitar seus direitos humanos, de atuar com legalidade e fazer respeitar, de procurar e administrar a justiça, e prevenir e erradicar a violência que o ocasiona. O feminicídio é um crime de Estado. (LAGARDE, 2008, p. 234).

Outro estudo sobre os feminicídios é do caso da Costa Rica na América Central, as pesquisadoras Montserrat Sagot e Ana Carcedo analisaram a realidade dos assassinatos de mulheres. Assim como Lagarde, Sagot e Carcedo utilizaram o conceito original de Russell, mas optaram por traduzir com a grafia femicídio.

Sagot e Carcedo afirmam que a violência contra mulher tem causado mais mortes que a malária, a AIDS ou a guerra. As ideias de paz e segurança estão fortemente associadas à instituição família no mundo ocidental, porém as autoras discutem que esta é uma visão conservadora que não revela a experiência de meninas e mulheres que têm na família o grupo social mais violento e a casa (hogar) o local mais inseguro. Segundo suas reflexões, não existe uma estimativa exata sobre as magnitudes da violência baseadas na desigualdade de gênero e seus impactos pelo alto sub-registro. Porém, muitas pesquisas vêm tornando cada vez mais evidente a sua existência (SAGOT; CARCEDO, 2006, p. 405).

Para Sagot e Carcedo (2006), a violência baseada na iniquidade de gênero figura como causa significativa de enfermidade e mortalidade feminina. As pesquisadoras coletaram informações estatísticas sobre assassinato de mulheres na Costa Rica por razões associadas à iniquidade de gênero, no período de 1990 a 1999. Analisaram a relação entre a vítima e o agressor, o lugar da ocorrência, a forma e as condições em que as mulheres foram mortas, ajudas prévias solicitadas pelas mulheres e as respostas encontradas. A finalidade do estudo foi a construção de propostas de prevenção e proteção para mulheres em risco de morte por violência baseada na iniquidade de gênero (SAGOT; CARCEDO, 2006, p. 409). 
A pesquisa adotou como marco teórico os saberes sobre a socialização de gênero, ${ }^{5}$ violência ${ }^{6}$ e femicídio. Para Sagot e Carcedo, o conceito de femicídio "ajuda a desarticular os argumentos de que a violência baseada na iniquidade de gênero é um assunto pessoal ou privado e mostra seu caráter profundamente social e político, resultado das relações de poder entre homens e mulheres na sociedade" (SAGOT; CARCEDO, 2006, p. 413).

As pesquisadoras entenderam o femicídio, como:

Se entende por femicídio o assassinato de mulheres por razões associadas com seu gênero. O femicídio é a forma mais extrema da violência baseada na iniquidade de gênero, entendida esta como a violência exercida pelos homens contra as mulheres em seu desejo de obter poder, dominação ou controle. Inclui os assassinatos produzidos pela violência intra-familiar e sexual (SAGOT; CARCEDO, 2006, p. 414).

Partindo desta definição inicial desenvolvem a tipologia: femicídio íntimo, não íntimo e por conexão. O femicídio íntimo ${ }^{7}$ refere-se aos assassinatos cometidos por homens com quem as vítimas tinham alguma relação íntima, familiar, de convivência, ou de afinidade. O femicídio não íntimo refere-se aos assassinatos cometidos por homens com quem a vítima não tinha relações íntimas, familiares, de convivência, ou afinidade a estes. Geralmente envolve a agressão sexual. O femicídio por conexão refere-se ao assassinato de mulheres que foram assassinadas "na linha de fogo" de um homem tratando de matar outra mulher. Aparecem aqui as mulheres em contexto familiar, as crianças ou outras mulheres que tentaram intervir ou que simplesmente foram pegas na ação do femicida (SAGOT; CARCEDO, 2006, p. 414).

Portanto, segundo as autoras, as principais características definidoras do femicídio seriam o tipo de conexão entre vítima e o agressor, e as circunstâncias de ocorrência. Como metodologia, elas elaboram uma lista contendo todas as

5 Todas as sociedades estabelecem mecanismos precisos para que os seres humanos aprendam os comportamentos e atitudes considerados adequados para cada expectativa de gênero, processo chamado de socialização de gênero. Processo que não é neutro e seu principal objetivo é forçar as pessoas a adaptarem-se às normas de uma sociedade estruturada com base na desigualdade e opressão de gênero. Controle social. Referência conceitual Andersen, 1988. (SAGOT; CARCEDO, 2006, p. 410).

6 "A violência contra mulheres é também um componente estrutural do sistema de opressão de gênero" (SAGOT; CARCEDO, 2006, p. 2011).

7 Importante ressaltar que o tipo femicídio íntimo já aparece como categoria nas apreciações de Diana Russell (1992). 
mulheres que foram mortas intencionalmente de 1990 a 1999 e pela leitura de cada uma das mortes reinterpretaram os dados que não constavam nos registros oficiais. Utilizaram fontes variadas para suprir as ausências de informações específicas. Elas estudaram os registros do "Libro de diagnósticos de Causas" da seção de patologia forense do Organismo de Investigacíon Judicial (OIJ); as notícias dos Jornais ${ }^{8}$ Extra, La Nacíon, La republica e La prensa; os registros do Anuário Estadístico Del Organismo de investigacíon Judicial (OIJ); ${ }^{9}$ o Libro de casos entradas Del OIJ; Expedientes de homicídios Del OIJ;10 e as Estadísticas Vitales Del Poder Judicial; y a los anuários del OIJ. ${ }^{11}$

Foram analisadas as relações dos homicídios de mulheres com os homicídios no geral, relação do homicídio de mulheres com os homicídios dos homens, relação dos homicídios das mulheres no geral e os femicídios, características das mulheres assassinadas e dos agressores, relações e situações de maior risco, nacionalidade, outras pessoas lesionadas na agressão, armas usadas, agressão sexual associada ao femicídio, antecedentes dos assassinos, suicídios, frequência de femicídios segundo província, relação com o agressor, lugar de ocorrência da morte, e sentenças condenatórias. As pesquisadoras concluíram que do total de 315 homicídios de mulheres na Costa Rica no período, 60\% eram propriamente femicídios, 13\% tinham tipo não identificado, segundo seus critérios de classificação, e em 17\% dos casos não foi possível defini-los como femicídio (SAGOT; CARCEDO, 2006).

Posteriormente, em estudo sobre os femicídios na América Central como um todo, Ana Carcedo desenvolveu o conceito de cenários do femicídios, definindo-os de acordo com os territórios que ocorrem: cenário familiar, cenário de relações conjugais, cenário de agressão sexual, cenário de sexo comercial, cenários históricos e novos cenários de femicídio, cenário de tráfico de mulheres para todos os tipos de exploração, palco de máfias nacionais e internacionais e redes criminosas, cenário de gangues, mulheres como território de vingança, cenário da misoginia, cenários entrelaçados (CARCEDO, 2010).

Desde o final da década de 1990 nota-se um movimento crescente de ativistas e intelectuais feministas latino-americanas e caribenhas em estabelecer parâmetros locais para a análise das mortes específicas de mulheres sob o conceito de

8 Informações sobre a morte e possíveis suspeitos e relação com as vítimas. Além de informações sobre ocorrências de agressões anteriores, a forma como esta mulher morreu ou onde foi encontrado seu corpo, se houve testemunhas ou outras pessoas lesionadas, e o que o assassino fez após o assassinato.

9 Onde se buscou dados sobre os assassinatos e as relações entre vítima e assassino.

10 Para confirmar a informação das outras bases.

11 Para a realização de comparações entre os dados referentes aos femicídios e os outros tipos de assassinatos e também outras mortes violentas, para mulheres e para homens. 
feminicídios/femicídios, especialmente grupos feministas de Honduras, Guatemala e Perú. Existe um esforço em relacionar o fenômeno às ausências dos Estados na prevenção, punição e erradicação das mortes e também a busca por evidenciar a relação destas mortes aos contextos políticos nacionais, fronteiras, guerras insurgentes (Colômbia), ditaduras militares, desparecimento de mulheres em contextos políticos de golpe (Honduras), conflitos por terra e perseguição a lideranças dos movimentos indígenas (Brasil), avanço do neoliberalismo, genocídio, fundamentalismos religiosos, as políticas sexuais de controle do corpo feminino e saúde reprodutiva das mulheres. O esforço argumentativo até aqui foi para situar o Brasil no quadro transnacional do fenômeno dos feminicídios.

\section{ADOÇÃO DO CONCEITO NO BRASIL: ÂMBITO ACADÊMICO E POLÍTICO}

A primeira publicação brasileira sobre os feminicídios foi o livro Femicídio: algemas do (In) visível de autoria da pesquisadora Sueli Almeida, 1998. No livro, é desenvolvida argumentação sobre a categoria "femicídio íntimo", o termo femicídio foi utilizado para explicar o caráter sexista dos crimes conjugais, "desmascarando a aparente neutralidade dos termos homicídio e assassinato", além de revelar o fenômeno que integra a política sexual de apropriação das mulheres. A referência utilizada são os estudos propostos na coletânea de Russell e Radford, 1992 (AlmEIDA, 1998).

Almeida esboçou inicialmente a discussão em sua tese de doutoramento em Ciências Sociais defendida na PUC de São Paulo, sob a orientação da socióloga feminista marxista Heleieth Iara Bongiovani Saffioti, em 1996. Para a autora "os homicídios ou tentativas não são casuais, nem fenômenos isolados, eles resultam do caráter intensivo e extensivo da violência de gênero, e em particular de sua versão doméstica”. O femicídio era para ela um termo que evidenciavam o caráter sexista dos homicídios no contexto conjugal heterossexual (AlmeidA, 1998, p. 43).

A pesquisadora aponta para a inexistência de registros para a elaboração da história dos femicídios, isso porque somente nas últimas décadas que começaram a ser compilados dados sobre homicídios desagregados por sexo (desde 1979 no Sistema de Informação de Mortalidade), além da ausência de informação sobre os agressores. Almeida conclui que a produção de dados sobre os homicídios segundo sexo e tipo de relação entre vítima e o agressor são primícias para o desenvolvimento de estudos do femicídio e, portanto, "ao se recusar a conhecer a extensão dos fenômenos da violência doméstica e do femicídio, o Estado colabora para ocultar a história de extrema opressão de amplos segmentos de mulheres" (Almeida, 1998, p. 43). 
Outro tema que habitava as preocupações da pesquisadora eram os assassinatos de homens por suas (ex) esposas e (ex) companheiras, o que ela nomeou como a "outra face do femicídio". Seus estudos abordavam as diferentes formas de participação dos autores dos homicídios conjugais consumados e tentados. A pesquisadora analisou 18 histórias das quais 7 mulheres foram vítimas de homicídios no contexto de relações conjugais, 4 foram vítimas de tentativas de homicídio, nas quais uma foi alvejada na linha de frente do confronto entre sua irmã e seu cônjuge, e encontrou 7 homicídios de homens em relações conjugais; as informações foram capturadas nos tribunais do Rio de Janeiro. Constatou que, nas situações em que os homens foram vítimas de homicídios conjugais, as mulheres estavam procurando se defender de agressões ou sofriam de um processo longo de agressões (AlmeidA, 1996, p. 44-45; AlmeidA, 1998). Uma visão mais centrada nos riscos da mulher numa relação conjugal.

Durante a década que se seguiu houve muita luta promovida pelos movimentos sociais de mulheres, feministas e de mulheres negras buscando fazer a transição da discussão sobre crimes conjugais para os feminicídios com foco no acesso à justiça. Um exemplo emblemático é a publicação do livro Do silêncio ao grito contra a impunidade: o caso Marcia Leopoldi, escrito pela irmã da vítima, Deise Leopoldi e a União de Mulheres de São Paulo, ${ }^{12}$ de 2007. No livro é feita a denúncia do caso de feminicídio de Márcia Leopoldi por seu ex-namorado Lago, em 1984, e a saga da família em articulação ao movimento de mulheres por justiça frente à negligência da justiça brasileira para apurar e julgar crimes como este e os processos de advocacy via organismos internacionais de direitos humanos.

Abaixo se transcreve uma narrativa sobre o processo de denúncia à CIDH da OEA, pois é de suma importância compreender este trâmite que vem sendo a forma como os movimentos sociais enfrentam a negligência do Estado diante das mortes de mulheres:

[em 1996], a União de Mulheres de São Paulo, em conjunto com Cladem, Cejil e Human Rights Watch, elaborou uma petição denunciando o caso Márcia Leopoldi à Comissão Interamericana. Foi apresentada com fundamento no art. 12 da Convenção Interamericana para Prevenir, Punir e Erradicar a violência contra a mulher (Convenção do Belém do Pará). Tal artigo expressa o direito de qualquer pessoa ou entidade não governamental juridicamente reconhecida em Estados-

12 A união de mulheres de São Paulo foi fundada em 1981, por trezentas mulheres do movimento feminista paulistano, suas origens vêm da luta das mulheres pelo fim da ditadura militar e pela redemocratização do país. 
-membros da Organização de apresentar à Comissão denúncias ou queixas de violação de políticas destinadas a prevenir, punir e erradicar a violência (LEOPOLDI, 2007, p. 115).

O livro faz menção ao conceito de femicídio nos termos de Russell e Radford, 1992. No texto são mencionadas as dificuldades de encontrar a quantidade de homicídios que seriam femicídios no Brasil, e que os estudos sobre eles são escassos perante a quantidade de cobertura midiática sobre casos de assassinatos de mulheres:

O assunto é tratado de forma sensacionalista, como um 'espetáculo'. Haja vista que têm sido televisionadas, por horas e dias, situações de violência contra a mulher, cujas cenas a população acompanha como se fosse uma novela, impregnadas de ficção e comentários sexistas (LEOPOLDI, 2007, p. 177).

O caso de feminicídio sofrido por Leopoldi é bastante parecido ao de Maria da Penha, até mesmo no processo de busca por acionar mecanismos internacionais de direito das mulheres. Em maio de 1983, Maria da Penha dormia quando o então marido, Viveros, deu um tiro em suas costas. Ele simulou que o caso se tratava de um assalto e ela ficou paraplégica. Após quatro meses no hospital, ao voltar para casa, em Recife, sofreu novamente tentativa de assassinato, a farsa foi descoberta. Em 1998, passados quinze anos do crime, o agressor de Maria da Penha foi julgado e condenado duas vezes e em ambas saiu livre do fórum devido a recursos. Por esta negligência do Estado brasileiro em agir perante a este e outros diversos crimes contra mulheres, organizações sociais deram entrada em denúncia à Comissão Interamericana de Direitos Humanos da Organização dos Estados Americanos via Centro pela Justiça e o Direito Internacional (CEJIL) e o Comitê Latino-Americano e do Caribe para a Defesa dos Direitos da Mulher (Cladem).

Em 2001 o Brasil foi condenado por omissão, tolerância e impunidade com que tratava os casos de violência doméstica, e foi instruído a iniciar mudanças na legislação para coibir a violência contra a mulher e pagar reparações à Maria da Penha. A Lei $n^{0} 11.340$ acabou sendo apelidada pelo nome de Maria da Penha, pois a sua elaboração tanto dialogava com os acordos internacionais de direitos das mulheres quanto respondia a medidas que deveriam ser implantadas pós-condenação na Corte Interamericana de Direitos Humanos. No caso da Lei Maria da Penha existe a menção às mortes por violência doméstica, mas não há um item específico utilizando o termo feminicídio, ou femicídio. 
Em outubro de 2008, ganha visibilidade o conceito e agora grafado como feminicídio, no texto de duas ativistas feministas, Maria Dolores de Brito Mota ${ }^{13}$ e Maria da Penha Maia, ao discutirem o sequestro e morte da adolescente Eloá Cristina Pimentel, 15 anos, por seu ex-namorado, motivado pela "recusa em aceitar o fim do relacionamento". O caso ocorreu na região do ABC, na grande São Paulo, e foi emblemático para a opinião pública brasileira. Durante os 4 dias em que a jovem fora mantida em cárcere privado, a imprensa cobria tudo do lado de fora do conjunto habitacional na periferia de Santo André, onde residia a jovem, onde foi mantida em cativeiro e assassinada.

O caso ocorreu no dia 13 de outubro de 2008, a jovem Eloá foi persuadida pelo ex-namorado a deixá-lo entrar em sua residência para dialogar após recusa em reatar a relação. Na ocasião, a jovem estava com a melhor amiga Naiara, e mais dois colegas de escola do sexo masculino, Iago e Victor. No momento em que entrou armado anunciou suas intenções. Após negociação com a polícia, os jovens do sexo masculino foram libertos, em seguida a amiga Naiara, com exceção de Eloá que permaneceu em cárcere sendo agredida e torturada. Após nova negociação policial, os oficiais solicitaram que Naiara tentasse negociar com o agressor a soltura da amiga, neste momento ela foi recapturada. Houve muito diálogo fraterno entre os policiais e o agressor. Os oficiais cometeram sucessivas falhas e declaravam à imprensa sua vontade de preservar a vida e integridade moral do sequestrador que, na opinião deles, era apenas um jovem apaixonado (VIANNA, 2010).

"(Lindemberg) bateu na vítima, acusou, expôs, coagiu e por fim martirizou o seu corpo com um tiro na virilha, local de representação da identidade sexual, e na cabeça, local de representação da identidade individual”, o agressor também vitimou a amiga da jovem com tiro na boca, durante o tempo que também a manteve como refém (Mota; Fernandes, 2008).

As autoras entendem que o assassinato de Eloá foi um feminicídio que para elas "é um crime de ódio, realizado sempre com crueldade, como o 'extremo de um continuum de terror antifeminino, incluindo várias formas de violência até alcançar o nível da morte pública [...] Assim o feminicídio é um crime de poder, é um crime político. Juridicamente é um crime hediondo, triplamente qualificado: motivo fútil, sem condições de defesa da vítima, premeditado" (Mota; Fernandes, 2008). Desta forma reaparece o conceito, mas agora com a grafia feminicídios,

13 Socióloga, professora adjunta da Universidade Federal do Ceará, lotada no Instituto de Cultura e Arte. 
apoiado no estudo da antropóloga Rita Laura Segato, Que és um feminicídio, 2006, como base conceitual.

Nos textos de Rita Segato (2006), é possível averiguar que a discussão principal também recai sobre o questionamento sobre se o conceito feminicídio deve incluir todos os assassinatos de mulheres ou se deveria ser uma categoria mais restrita. No seu entendimento, elaborar uma tipologia específica para os casos de feminicídios permitiria criar dados mais precisos e facilitar a identificação dos culpados. Desta maneira, seriam necessárias também categorias jurídicas precisas a respeito dos autores para a obtenção de informações mais especializadas sobre os feminicídios. Para ela, ao definir essas especificidades seria possível traçar um paralelo entre a categoria feminicídio e genocídio. Em texto de 2011, Segato defende feminicídio como um "conjunto de violências dirigidas especificamente à eliminação das mulheres por sua condição de mulheres", sendo necessário elevar a categoria de feminicídio a um nível equivalente ao de "genocídio" (SEgATo, 2006; 2011, p. 6).

No campo das políticas públicas, nota-se a partir de 2010 uma amplificação de esforços no âmbito das políticas e lutas feministas pelos direitos das mulheres para inserir os feminicídios como categoria jurídica em diversos países inclusive no Brasil. Um primeiro sinal da transnacionalização do conceito nos países da América Latina e Caribe pode ser vistos nos documentos elaborados pela XI Conferencia Regional sobre la Mujer de América Latina y el Caribe, realizada em Brasília em 2010, que contou com a participação de mulheres da política dos Estados e ativistas dedicadas a promoção e defesa dos direitos das mulheres em prol da igualdade de gênero com ênfase na autonomia e no empoderamento econômico. No documento os termos feminicídio e femicídio aparecem no tópico destinado às recomendações para ampliar a participação das mulheres nos processos de tomada de decisão e esferas de poder. Nele, a violência femicida contra as mulheres aparece como impedimento a alcançar essa participação, nos seguintes termos:

f) Incorporar en las políticas de seguridad pública medidas específicas para prevenir, investigar, sancionar, penalizar y erradicar el femicidio y el feminicidio, entendidos como la forma más extrema de violencia de género contra las mujeres (Cepal de las Mujeres, 2010, p. 8).

Wânia Pasinato apresenta discussão sobre as implicações políticas da escolha pela categoria femicídio (a autora acreditava que existia duas formas de grafar a categoria e que a escolha por femicídio ou feminicídio não impactava em diferenças conceituais para a realidade latino-americana e brasileira), no artigo "Femicídios 
e as mortes de mulheres no Brasil” de 2011. A pesquisadora trouxe com seu artigo revisão bibliográfica sobre o tema fazendo referência às reflexões de Russell e Radford (1992), apontando para a inexistência ou falta de acesso a informações disponíveis que possibilitem a análise dos casos na América Latina. Segundo Pasinato, para contornar este obstáculo a maior parte dos estudos vem recorrendo às informações difundidas na impressa e múltiplas fontes oficiais e sociais como, por exemplo, processos criminais e reportes internacionais. $\mathrm{O}$ artigo busca definir, delimitar e pensar quais os avanços que a categoria "femicídios" pode ou não trazer (PASInATo, 2011).

Para Pasinato:

Um dos maiores obstáculos para os estudos sobre mortes de mulheres, e sobre os homicídios de forma geral, no Brasil é a falta de dados oficiais que permitam ter uma visão mais próxima do número de mortes e dos contextos em que ocorrem. Os estudos e relatórios sobre a situação dos femicídios em países da América Latina não enfrentam situação diferente. A maior parte dos trabalhos aponta para a falta de dados oficiais, a ausência de estatísticas desagregadas por sexo da vítima e de outras informações que permitam propor políticas de enfrentamento para esta e outras formas de violência que atingem as mulheres. Em muitos casos a estratégia adotada pelos estudos acaba sendo a utilização de dados provenientes de diferentes fontes - como registros policiais, registros médicos-legais, processos judiciais, documentos do Ministério Público e, uma das fontes mais comuns, a imprensa escrita [...] sua utilização pode resultar em dados bastante frágeis dos pontos de vista metodológico e científico [...] existe diferentes sistemas de classificação (Pasinato, 2011, p. 233).

A autora compara a categoria femicídio e sua tendência a englobar todas as mortes de mulheres ao "método da amálgama" de Elisabeth Badinter (2005), que segundo ela é aplicado sempre que se tenta dar expressão numérica aos crimes contra as mulheres os unificando. A homogeneização de todos os assassinatos de mulheres numa única categoria é a maior crítica da autora que argumenta sobre a fragilidade de impacto político, caso não sejam consideradas características específicas das vítimas, como idade, raça/cor, grupo sócio-ocupacional a qual pertence, por exemplo, e o contexto no qual o crime ocorre. (PAsinato, 2011).

Do ano de 2010 a diante se multiplicam os estudos acadêmicos e iniciativas dos movimentos sociais sobre os feminicídios. Outro exemplo foi o texto das pesquisadoras do IPEA Leila Posenato Garcia, Lúcia Rolim Santana de Freitas, Gabriela 
Drummond Marques da Silva e Doroteia Aparecida Höfelmann, que explora os dados sobre mortes por agressão disponibilizadas pelo sistema de informação de Mortalidade (SIM/DATASUS), no período de 2001 a 2011 (GARCIa et al., 2013). Para elas os feminicídios/femicídios são as mortes de mulheres decorrentes de conflitos de gênero, pelo fato de serem mulheres, descrevem que estas mortes são geralmente perpetradas por homens de relação da mulher e decorrem de situações em que a mulher tem menos poder em relação ao homem. (GARCIA et al., 2013).

Em 2013, no âmbito legislativo e jurídico, foi nomeada a Comissão Parlamentar Mista De Inquérito da Violência Contra a Mulher, CPMIVCM, com o objetivo de "investigar a situação da violência contra a mulher no Brasil e apurar denúncias de omissão por parte do poder público com relação à aplicação de instrumentos instituídos em lei para proteger as mulheres em situação de violência”. Dentre as proposições do relatório final da CPMI investiu-se em projeto de lei para tipificar e incluir o feminicídio dentro do Código Penal brasileiro, a CPMIVCM já havia ocorrido em duas outras oportunidades em 1992 e 2003 (CPMIVCM - SENADo FEDERAL, 2013).

A curva ascendente de feminicídios (o assassinato de mulheres pelo fato de serem mulheres), a permanência de altos padrões de violência contra mulheres e a tolerância estatal detectada tanto por pesquisas, estudos e relatórios nacionais e internacionais quanto pelos trabalhos desta CPMI estão a demonstrar a necessidade urgente de mudanças legais e culturais em nossa sociedade. Conforme mostra a pesquisa intitulada Mapa da Violência: Homicídios de Mulheres, mais de 92 mil mulheres foram assassinadas no Brasil nos últimos trinta anos, 43 mil delas só na última década. É preciso dar um basta nas diversas manifestações de violência contra as mulheres, sobretudo em sua forma extrema: o assassinato [...] Importa considerar, ainda, no tocante ao feminicídio, a existência de recomendações internacionais para a sua tipificação, a exemplo daquelas inscritas no Relatório sobre Violência contra Mulheres, suas Causas e Consequências, assinado por Rashida Manjoo, assim com Conclusões Acordadas da Comissão sobre o Status da Mulher, em sua $57^{\text {a }}$ Sessão, em 15 de março de 2013. Esses e outros instrumentos internacionais estão a exigir uma resposta legislativa contra tal fenômeno, motivo por que leva este Colegiado a apresentar um projeto de lei tipificando o feminicídio (CPMIVC - SENAdo Federal, 2013, p. 8). 
O projeto propunha que o feminicídio entrasse como agravante do homicídio no Código Penal, com pena de reclusão de 12 a 30 anos, tipificando-o como assassinatos de mulheres com circunstâncias de violência doméstica ou familiar, violência sexual, mutilação ou desfiguração da vítima (CPMIVCM - SENAdo FEDERAL, 2013, p. 998 e 1002).

Para a comissão,

A importância de tipificar o feminicídio é reconhecer, na forma da lei, que mulheres estão sendo mortas pela razão de serem mulheres, expondo a fratura da desigualdade de gênero que persiste em nossa sociedade, e é social, por combater a impunidade, evitando que feminicidas sejam beneficiados por interpretações jurídicas anacrônicas e moralmente inaceitáveis, como o de terem cometido “crime passional”. Envia, outrossim, mensagem positiva à sociedade de que o direito à vida é universal e de que não haverá impunidade. Protege, ainda, a dignidade da vítima, ao obstar de antemão as estratégias de se desqualificarem, midiaticamente, a condição de mulheres brutalmente assassinadas, atribuindo a elas a responsabilidade pelo crime de que foram vítimas. (CPMIVC - SENADO FEDERAL, 2013, p. 1004).

Como consequência dos debates e ações, em 9 março de 2015, a lei contra os feminicídios foi aprovada no Brasil, dentro do Código Penal, como sendo um agravante aos casos de homicídio, artigo $121 \mathrm{CP}$. Desta forma, foi definido o feminicídio como sendo os homicídios cometidos contra a mulher por razão da condição de sexo feminino, definida como: violência doméstica e familiar e menosprezo ou discriminação à condição de mulher. A pena poderá ser aumentada de 1/3 até a metade se o crime for praticado contra mulher durante a gestação ou nos 3 meses posteriores ao parto; contra pessoa menor de 14 (catorze) anos, maior de 60 (sessenta) anos ou com deficiência, na presença de descendente ou de ascendente da vítima (ONU, 2016; BRASIL, 2015).

O Brasil foi o $16^{\circ}$ país latino-americano com legislações punitivas ao feminicídios (Tabela 1). A discussão sobre os feminicídios já ganhou visibilidade no âmbito judicial e político em diversos países da América Latina e Caribe. Em alguns países, como no México, o Estado conta além da lei com mecanismos de monitoramento e diagnósticos aos feminicídios (ENDIREH). O Uruguai aprovou agora em 2017, se tornando $017^{\circ}$ país a possuir legislação punitiva para os feminicídio/femicídios. 
Tabela 1. Ano de promulgação de legislação punitivo aos feminicídios/femicídos. Paises Latino Americanos e Caribenhos.

\begin{tabular}{|l|c|}
\hline \multicolumn{1}{|c|}{ País } & Ano \\
\hline Costa Rica & 2007 \\
\hline Guatemala & 2008 \\
\hline Colômbia & 2008 \\
\hline Chile & 2010 \\
\hline El Salvador & 2010 \\
\hline Peru & 2011 \\
\hline Nicarágua & 2012 \\
\hline México & 2012 \\
\hline Argentina & 2012 \\
\hline Honduras & 2013 \\
\hline Bolívia & 2013 \\
\hline Panamá & 2013 \\
\hline Equador & 2014 \\
\hline Venezuela & 2014 \\
\hline República Domincana & 2014 \\
\hline Brasil & 2015 \\
\hline Uruguai & 2017 \\
\hline
\end{tabular}

Fonte:http://www.compromissoeatitude.org.br/legislacoes-da-america-latina-quepenalizam-o-feminicidio/ (Elaboração própria).

\section{CONCLUSÕES}

Diante do quadro exposto, considera-se que existe um esforço em definir quais parâmetros são centrais no conceito de feminicídios dentro da crítica feminista. No âmbito jurídico, notamos uma transnacionalização da figura penal do feminicídio como crime na ALC, e um histórico de trabalhos que buscam definir maneiras de medi-los como fenômeno social. É possível encontrar grafias diferentes do termo (femicídio e feminicídio), concorda-se que em países de língua castelhana e portuguesa a forma feminicídios elimina a associação direta a versão feminina do homicídio, o que seria um reducionismo e tiraria a potência da categoria que é exatamente questionar a aparente neutralidade dos termos jurídicos, como o homicídio.

Considera-se que os feminicídios são mortes específicas de mulheres. É destacada que a autoria das mortes é masculina no caso direto e do Estado, através de suas instituições e de grupos organizados, no caso indireto. Objetivamente podemos notar pelo exposto na bibliografia analisada que o caso de autoria indireto tem a ver com mortes ligadas às políticas sexuais de controle do corpo feminino e reprodução (procriação), violência sexual sistemática no caso das guerras e conflitos, e omissão perante aos casos diretos. O caso de autoria direto é composto de mortes causadas pela violência, como o suicídio, homicídio e causas externas 
indefinidas, não correspondem ao total destas mortes, mas representam grande parte delas.

A autora deste artigo apresenta como proposta de análise uma nova tipologia visando uma interpretação das formas mais básicas de feminicídios (Romio, 2017). Assim considera-se um feminicídio quando ele atenda a uma ou mais das seguintes condições,

Feminicídio reprodutivo, vinculado às políticas de controle do corpo e da sexualidade da mulher, cuja expressão mínima são as mortes por aborto.

Feminicídio doméstico, violência letal por agressão física contra a mulher no contexto domiciliar, conjugal ou familiar.

Feminicídio sexual, violência letal por agressão física contra a mulher por meio sexual.

\section{REFERÊNCIAS BIBLIOGRÁFICAS}

Almeida, Sueli. Femicídio: algemas (in) visíveis do público privado. Rio de Janeiro: Revinter, 1998.

Violência de gênero: público x privado. São Paulo, 1996. 355 p. Tese (Doutorado) - Pontifícia Universidade Católica de São Paulo.

CAPuti, Jane; Russell, Diana. "Femicide: Sexism against women”. In: RADFord, Jill; Russell, Diana E. H. Femicide: The Politics of Woman Killing. Great Britain: Open University Press: 1992, p. 13-21.

Carcedo, Ana. "Conceptos, contextos y escenarios del femicidio en centro América". In: Carcedo, Ana (Cord). No olvidamos ni aceptamos: Femicidio en Centroamérica 2000 - 2006 / CEFEMINA. - 1 ed. - San José: C.R.: 2010.

Cepal De Las Mujeres. CONSENSO DE BRASILIA. XI Conferencia Regional sobre la Mujer de América Latina y el Caribe, Brasília, 2010.

Falquet, Jules. "De los asesinatos de Ciudad Juárez al fenómeno de los feminicidios: ¿nuevas formas de violencia contra las mujeres?”, 2014.

Fernandes, Maria da Penha Maia; Mota, Maria D. de Brito. Feminicídio ao vivo: o que nos clama Eloá. Site Adital, 20/10/2008.

Garcia, Leila Posenato; Freitas, Lúcia Rolim Santana de; Silva, Gabriela Drummond Marques da; HöFELmann, Doroteia Aparecida. Violência contra a mulher: feminicídios no Brasil. Texto para Discussão - TD. Ipea, 2013.

Hester, Marriane. "The witch-craze in sixteenth- century England as social control of women”. In: RADFord, Jill; Russell, Diana E. H. Femicide: The Politics of Woman Killing. Great Britain, Open University Press: 1992, p. 27-39.

Kelly, Liz. Surviving Sexual Violence. Cambridge: Polity Press, 1988. 
La Botz, Dan. "MÉXICO: Girl's Murder Sad Symbol of Corporate Power, Child Labor, Female Exploitation on the Border". In: Mexican Labor News and Analysis March 2nd, 1999.

LAgARde, Marcela. "Presentación ». In: La Violencia feminicida en 10 entidades de la Republicana mexicana. Congrès de l'Unión, Camara de diputados, México DF: 2006. LEOPOLDI, Deise. Do silêncio ao grito contra a impunidade: O caso Márcia Leopoldi. São Paulo: União das Mulheres de São Paulo, 2007.

ManjoO, Rashida. Report of the Special Rapporteur on violence against women, its causes and consequences. United Nations A/HRC/20/16. 2323 May 2012.

ONu. ONU Mulheres Brasil. Diretrizes Nacionais para Investigar, Processar e Julgar com perspectiva de Gênero as Mortes Violentas de Mulheres - Feminicídios. Brasília: ONU Mulheres, 2016.

Pasinato, Wânia. 'femicídios' e as mortes de mulheres no Brasil. Cadernos Pagu (37), p. 219-246, julho - dezembro, 2011.

Romio, Jackeline Aparecida Ferreira. Feminicídios no Brasil, uma proposta de análise com dados do setor de saúde [tese de doutorado] - Campinas, 2017.

RADFord, Jill; Russell, Diana E. H. Femicide: The Politics of Woman Killing. Great Britain: Open University Press: 1992.

Russell, Diana; De Ven, Nicole Van (ed.). Crimes Against Women: Proceedings of the International Tribunal. $3^{\text {rd }}$ ed. .California: Russell Publications, 1990.

Russell, Diana. Fala sobre as origens dos feminicídios, dezembro de 2011. http://www. dianarussell.com/origin_of_femicide.html. Acesso em: 31/05/2019.

SAGOT, Montserrat; CARCEDO, Ana. "Cuando la violencia contra las mujeres mata: femicídio en Costa Rica, 1990-1999”. In: CORRÊA et al. (orgs.) Vida em Família: uma perspectiva comparativa sobre "crimes de honra". Campinas, Núcleo de Estudos de Gênero-Pagu/ UNICAMP, 2006, p. 405-438.

Segato, Rita Laura. Que és un feminicídio. Notas para un debate emergente. Brasília: UnB, 2006.

Segato, Rita Laura. Femi-geno-cidio como crimen en el fuero internacional de los derechos humanos: el derecho a nombrar el sufrimiento en el derecho. In: Fregoso, Rosa-Linda; Bejarano, Cynthia (Eds.). Feminicidio en América Latina. Mexico, DF: Centro de Investigaciones de Ciencias Sociales y Humanidades; Universidad Nacional Autónoma de México, 2011, p. 245-248.

Vianna, Cynthia Semíramis Machado. O caso Eloá: análise da abordagem de feminicídio na mídia. Trabalho apresentado no Fazendo Gênero 9, UFSC: Santa Catarina, Setembro de 2010. 